\title{
Calcifying Tendonitis of the Ankle, Effectivenness of 5\% Acetic Acid Iontophoresis and Ultrasound over Achiles Tendon: A Prospective Case Series
}

Marcos E Fernández-Cuadros ${ }^{1,2 *}$, Olga S Pérez-Moro², María Jesús Albaladejo-Florin², Ruben AlgarraLópez $^{2}$ and Luz Casique-Bocanegra ${ }^{1}$

${ }^{1}$ Rehabilitation Department, Santísima Trinidad's General Foundation Hospital, Salamanca, Spain

${ }^{2}$ Rehabilitation Department, Santa Cristina's University Hospital, Madrid, Spain

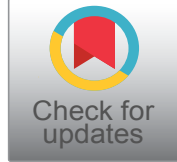

*Corresponding author: Marcos E Fernández-Cuadros, PhD, Rehabilitation Department, Santa Cristina's University, Santísima Trinidad's General Foundation Hospital, Salamanca, Spain, Calle Maestro Vives 2, CP 28009, Madrid, Spain

\begin{abstract}
Objective: To conduct a prospective Multicentre Quasiexperimental before-and-after study (Non-Randomized Control Trial) to demonstrate the effectiveness of Acetic Acid Iontophoresis and Ultrasound in the treatment of Calcifying Tendonitis (CT) of the ankle.

Material and methods: Prospective, multicentre, quasiexperimental before-after intervention study, to 10 patients who attended to both Rehabilitation Departments, at Santísima Trinidad's General Foundation Hospital, Salamanca-Spain and at Santa Cristina's University Hospital, Madrid-Spain, from June-2014 to December-2018.

Outcome measures: 1) Pain: Measured by Visual Analogical Scale (VAS); 2) Calcification size: In millimetres $(\mathrm{mm})$, both measured radiologically at the beginning/end of treatment.
\end{abstract}

Intervention: Iontophoresis with $5 \%$ acetic acid at $4.7 \mathrm{~mA}$ $\times 10$ minutes and continuous Ultrasound $1 \mathrm{~W} / \mathrm{cm}^{2} / 1 \mathrm{MHz} \times$ 5 minutes over calcification.

Results: Mean age 49.2 \pm 7.28 -years $(n=10)$. Female $50 \%$ $(n=5)$. Average number of sessions was $21.7 \pm 7.22$.

Treatment showed a significant amelioration of pain measured by VAS from $7.9 \pm 1.66$ to $2.8 \pm 2.09$ points $(p=$ 0.0002 ). Calcification size diminished significantly from $10 \pm$ 5.3 to $5.3 \pm 5.22 \mathrm{~mm}(\mathrm{p}=0.0186)$.

Conclusions: CT is more common in middle-aged people. In our study, CT affects similarly both male and female.

Iontophoresis with 5\% Acetic Acid and Ultrasound is a safe, simple and inexpensive technique. Twenty sessions of $5 \%$ acetic acid iontophoresis plus Ultrasound are capable of reducing significantly pain and size of calcification on Achilles' tendon at the ankle.

This study shows a level of evidence II-1 and grade of recommendation $B$ that allows us to postulate Acetic Acid iontophoresis and ultrasound as an effective treatment in CT.

\section{Keywords}

Iontophoresis, Ultrasound, Calcifying tendonitis, Achilles tendon, Physical therapy

\section{Introduction}

Calcifying tendonitis (CT) is defined as the deposit of hydroxyapatite within tendons and tendon sheaths. It occurs in up to $3 \%$ of adults and is the cause of $40-54 \%$ of painful shoulder symptoms [1-3].

The etiology of CT is considered multifactorial, playing degeneration an important role. Certain tendons are particularly vulnerable to $\mathrm{CT}$. These include elements of the rotator cuff, Achilles, Patella, forearm extensors, biceps brachi and tibialis posterior tendon [4]. CT etiology and pathogenesis remain unclear [4] and is still a matter of controversy [5]. In 1872, Duplay described CT as a cause of shoulder pain. Degenerative changes, hypovascularization of the rotator cuff, metabolic abnormality and overuse have been suggested as possible causes for calcification of the tendon tissue [3]. According to

Citation: Fernández-Cuadros ME, Pérez-Moro OS, Albaladejo-Florin MJ, Algarra-López R, Casique-Bocanegra LO (2019) Calcifying Tendonitis of the Ankle, Effectivenness of 5\% Acetic Acid Iontophoresis and Ultrasound over Achiles Tendon: A Prospective Case Series. Int J Foot Ankle 3:023.

Accepted: February 11, 2019; Published: February 13, 2019

Copyright: (c) 2019 Fernández-Cuadros ME, et al. This is an open-access article distributed under the terms of the Creative Commons Attribution License, which permits unrestricted use, distribution, and reproduction in any medium, provided the original author and source are credited. 
Uhthoff and colleagues, the deposition of calcium apatite crystals within the substance of the tendon is not a degenerative process but one that is actively mediated by cells in a viable tendon $[5,6]$.

Three stages with clinical/histological/radiological correlation are described, and sometimes overlap: 1) Pre-calcification: tenocyte metaplasia and chondrocyte transformation; 2) Calcification: a) formative (reservoir of vesicles in matrix), b) Resorptive (spontaneous resorption by macrophages/multinucleated cells by phagocytosis); post-calcification: collagen remodeling and tendon repair [7].

The clinical picture in $\mathrm{CT}$ is highly variable. There are asymptomatic patients (incidental radiological finding), patients with chronic pain and patients in acute painful crisis, mainly associated to the resorptive phase [8]. The diagnosis is clinical and radiologica [8]. CT treatment is initially conservative and depends on its evolutionary stage [8].

In most of the cases, CT is a self-limiting condition, in which the calcification spontaneously resorbs after a period of a few years or is treated successfully conservatively $[5,9]$. In the formative and resting phases of the disease, if conservative measures fail and the patient presents with progressive symptoms interfering with daily living activities, removal of calcific deposits may be indicated $[5,6]$.

Conservative treatment includes NSAIDs (nonsteroidal anti-inflammatory drugs), physiotherapy, electrotherapy (micro waves, short waves, TENS, ultrasounds, iontophoresis, interferential and pulsed electromagnetic therapy) [8]. Fernández-Cuadros, et al. have demonstrated recently that different electrotherapy techniques are useful reducing pain but not the calcification on CT patients [8].

Iontophoresis with acetic acid is a safe, common and cheap treatment and it was for decades the only option available, capable of acting over the calcification [8]. However, there is only a few clinical studies that support its effectiveness $[10,11]$; some of them are even controversial $[12,13]$. In a recent article, FernándezCuadros, et al. have stated the effectiveness of acetic acid iontophoresis and ultrasound on CT of the shoulder [7], but to the best of author's knowledge, there is no report on its effectiveness in other tendons apart from the rotator cuff, included Achilles' tendon.

The objective of the study is to demonstrate the effectiveness of Acetic Acid Iontophoresis and Ultrasound on $\mathrm{CT}$ of the ankle through a non-randomized multicentre control trial, which gives a good level of evidence-based medicine.

\section{Material and Methods}

\section{Design}

Prospective, not randomized, multicentre, quasi- experimental before-after control trial.

\section{Patients}

The study included 10 patients diagnosed clinically and radiologically of ankle CT who attended to either the Rehabilitation Department, at Santísima Trinidad's General Foundation Hospital, in Salamanca-Spain, or the Rehabilitation Department, at Santa Cristina's University Hospital, in Madrid-Spain, from June 2014 to December 2018 (54 months).

\section{Inclusion criteria}

1) All patients with clinical and radiological diagnostic of CT derived to the Rehabilitation Departments (from Traumatology, Rheumatology, Familiar Medicine, etc.); 2) Older than 18 years; 3) Who accepted the proposed treatment and firmed consent; 4) With pain greater than 3 on the Visual Analogical Scale (VAS).

\section{Exclusion criteria}

1) Any patient with electrical devices (pacemaker, electrical stimulator) which constitute formal contraindication to electrotherapy treatment; 2) Intolerance or allergy to acetic acid, erythema or burn caused by the treatment; 3) Osteoarthritis, inflammation or infection on the respective articulation; 4) Cancer or any other severe or mental diseases.

\section{Evaluation}

Socio-demographic data (age, sex, occupation, laterality, dominance, occupation), personal history (diseases, pacemakers, electrical stimulator), and radiological characterization of calcification (formative/ resorptive) were obtained. The treatment protocol was approved by the ethical committee of both Hospitals, and patients were given Informed Consent.

\section{Outcome measures}

1) Pain: measured by Visual Analogical Scale (VAS); 2) Calcification size: in millimetres $(\mathrm{mm})$; Both evaluated radiologically at the beginning/end of treatment.

\section{Intervention}

All diagnosed patients were given 5\% Acetic Acid lontophoresis, 2 cc dropped into a gauze and placed on a moistened cation (negative electrode), on the anterior aspect of the Achilles' tendon. The anion (positive electrode), also moistened, was placed at a distance of $10 \mathrm{~cm}$ from the cation (at the sole), to allow the passage of current flow. Both damp cloth coated electrodes were attached with a belt, allowing full contact, in order to avoid the risk of burning. A $4.7 \mathrm{~mA}$ galvanic current was applied for 10 minutes. Subsequently, continuous Ultrasound to an intensity of $1 \mathrm{~W} / \mathrm{cm}^{2} / 5$ minutes and a $1 \mathrm{MHz}$ frequency was applied over the affected tendon to promote drug absorption and to decrease pain [11].

To perform the treatment protocol, two European 
Medical Devices were used: 1) For lontophoresis, ENDOMED 581 ${ }^{1 \mathrm{D}}$ (EnrafNonius ${ }^{\circledR}$ CE 0197), located both in Salamanca-Spain and Madrid-Spain, were used; 2) For Ultrasound, SONOPULS 490 (EnrafNonius ${ }^{\circledR}$ CE 0197), both located on Salamanca-Spain and Madrid-Spain, were used.

\section{Follow-up}

Periodic reviews were performed (every 10 days) to assess pain and radiological change in size and/or disappearance of calcification by radiological evaluation. The minimum clinically significant change for pain measured by VAS corresponds to 1 point; it is considered a significant improvement if the change is greater than

Table 1: Description of variables of the study at baseline $(n=10)$.

\begin{tabular}{|l|l|}
\hline Variable & Value \\
\hline Age, years \pm SD & $49.2 \pm 7.28$ \\
\hline Male, $\mathrm{n} ; \%$ & $5 ; 50$ \\
\hline Ratio male:female & $1: 1$ \\
\hline Number of sessions \pm SD & $21.7 \pm 7.22$ \\
\hline Onset of symptoms, months \pm SD & $7.8 \pm 4.58$ \\
\hline Initial pain (graded from 0-10) & $7.9 \pm 1.66$ \\
\hline Initial size of calcification, mm & $10 \pm 5.3$ \\
\hline Radiographical evaluation, $\mathrm{n} ; \%$ & $10 ; 100$ \\
\hline Ultrasonographic evaluation, $\mathrm{n} ; \%$ & $5 ; 50$ \\
\hline
\end{tabular}

SD: Standard Deviation.
3 points [14,15]. The radiographic measurements of the calcification were made in millimetres $(\mathrm{mm})$, on $100 \%$-size, posterior anterior plain radiographs of the affected articulation, assessing the calcification in its longest axis. If there was more than one calcification, the full measure corresponded to the sum of these calcifications measured separately $[7,10]$. Clinical improvement included decreased pain (measured by VAS), the disappearance of the painful manoeuvres and functional mobility recovery.

\section{Statistical analysis}

SPSS ${ }^{\circledR} 20.0$ statistical package was used. For the analysis of quantitative descriptive variables, averages were used; while for qualitative variables, percentages and frequencies were used. To contrast the quantitative variables, paired T-test was used; while for qualitative variables, the $\mathrm{chi}^{2}$ test was used. The level of significance used was $95 \%(p<0.05)$.

\section{Results}

A total of 10 patients were recruited for this non-randomized quasi-experimental multicenter-control-trial. 8 patients corresponded to Santísima Trinidad's General Foundation Hospital and 2 patients corresponded to Santa Cristina's University Hospital.

Table 2: Outcome variables after intervention ( $5 \%$ acetic acid iontophoresis plus ultrasound) $n=10$.

\section{Outcome Variable}

Pain (graded from 0-10) \pm SD

Size of calcification, $\mathrm{mm} \pm \mathrm{SD}$

SD: Standard Deviation.

\section{Before}

$7.9 \pm 1.66$

$10 \pm 5.3$
After

$2.8 \pm 2.09$

$5.3 \pm 5.22$ p 0.0002 0.0186

\section{OUTCOME VARIABLE AFTER IONTOPHORESIS ACETIC ACID + SONOPHORESIS $(n=10)$}

12

10

8

6

4

2

0

BEFORE

AFTER

- Pain (graded from 0-10) \pm SD

- Size of calcification, $\mathrm{mm} \pm \mathrm{SD}$

Figure 1: Outcome variables after intervention ( $5 \%$ acetic acid iontophoresis plus ultrasound) $n=10$. SD: Standard Deviation. 
The mean age of the sample was $49.2 \pm 7.28$ years. As for gender, women were affected $(n=5 ; 50 \%)$ the same as men $(n=5 ; 50 \%)$. The mean time of pain was $7.8 \pm$ 4.5 months. All patients received a mean of $21.7 \pm 7.22$ sessions of $2 \%$ Acetic Acid Iontophoresis and Ultrasound treatment (Table 1).

Considering Pain as an outcome measure (measured by VAS), all of the patients diminished pain significantly. In CT of the Achilles tendon, pain reduced from $7.9 \pm 1.66$ to $2.8 \pm 2.09$ points $(p=0.0002$ ) (Table 2 and Figure 1 ).

With regard to the change in millimeters $(\mathrm{mm})$ of the calcification, all of the patients showed a decrease in the size of calcification. The radiological change in Achilles CT was significant; decreased from $10 \pm 5.3$ to $5.3 \pm 5.22$ $\mathrm{mm}(\mathrm{p}=0.0186)$, (Table 2, Figures 2, Figure 3, Figure 4, Figure 5 and Figure 6).

\section{Discussion}

The use of Acetic Acid lontophoresis with or without Ultrasound in the treatment of CT (mainly CT of the shoulder) is been for years the most frequently applied therapeutic modality in Rehabilitation Departments. However, there is a paucity of studies that support its use (Rioja-Toro, Chico-Alvarez, Fernández-Cuadros) $[7,10,11]$; even, there are other classic and conflicting studies (Perrón, Leduc) $[13,14]$. To the best of authors' knowledge, this is the first study that supports the use of Acetic Acid Iontophoresis and continuous Ultrasound in the treatment of CT of the ankle, other than case reports, with demonstrable scientific evidence and with a sample number higher than those previous studies [7,10-14].

CT is a common, painful, disabling disease, which
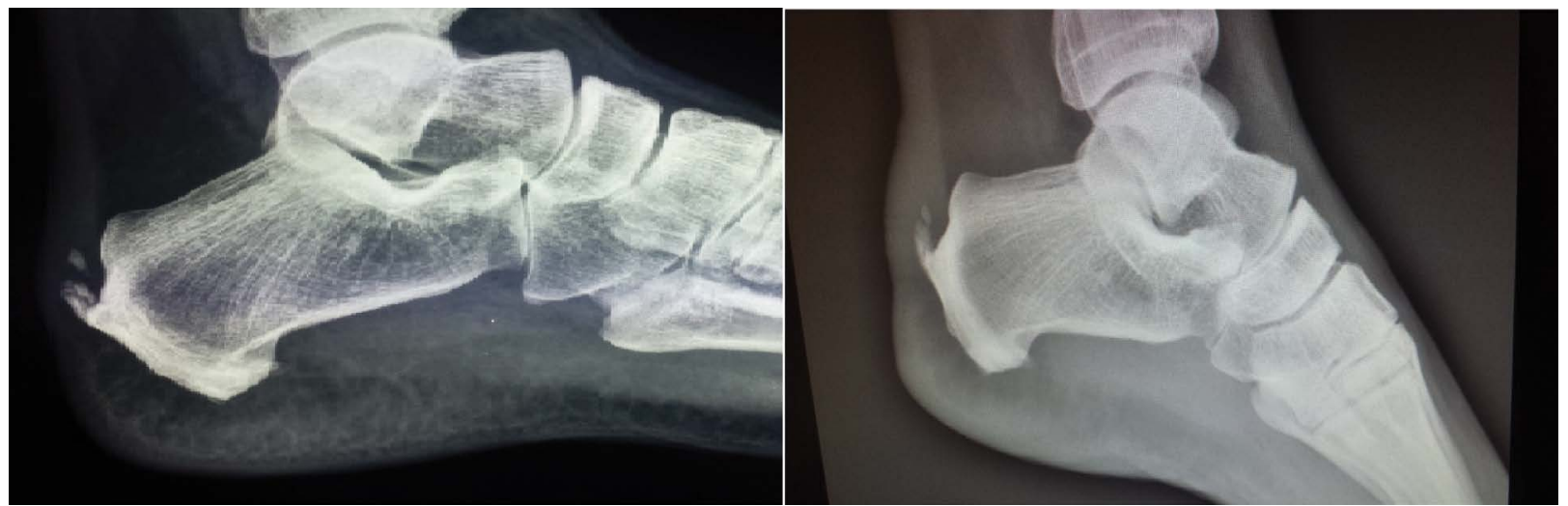

Figure 2: Case 1: In a 50-year-old female, after 10 sessions of treatment, pain decreased from $8 / 10$ to $1 / 10$ and size of calcification decreased from 12 to $6 \mathrm{~mm}$.

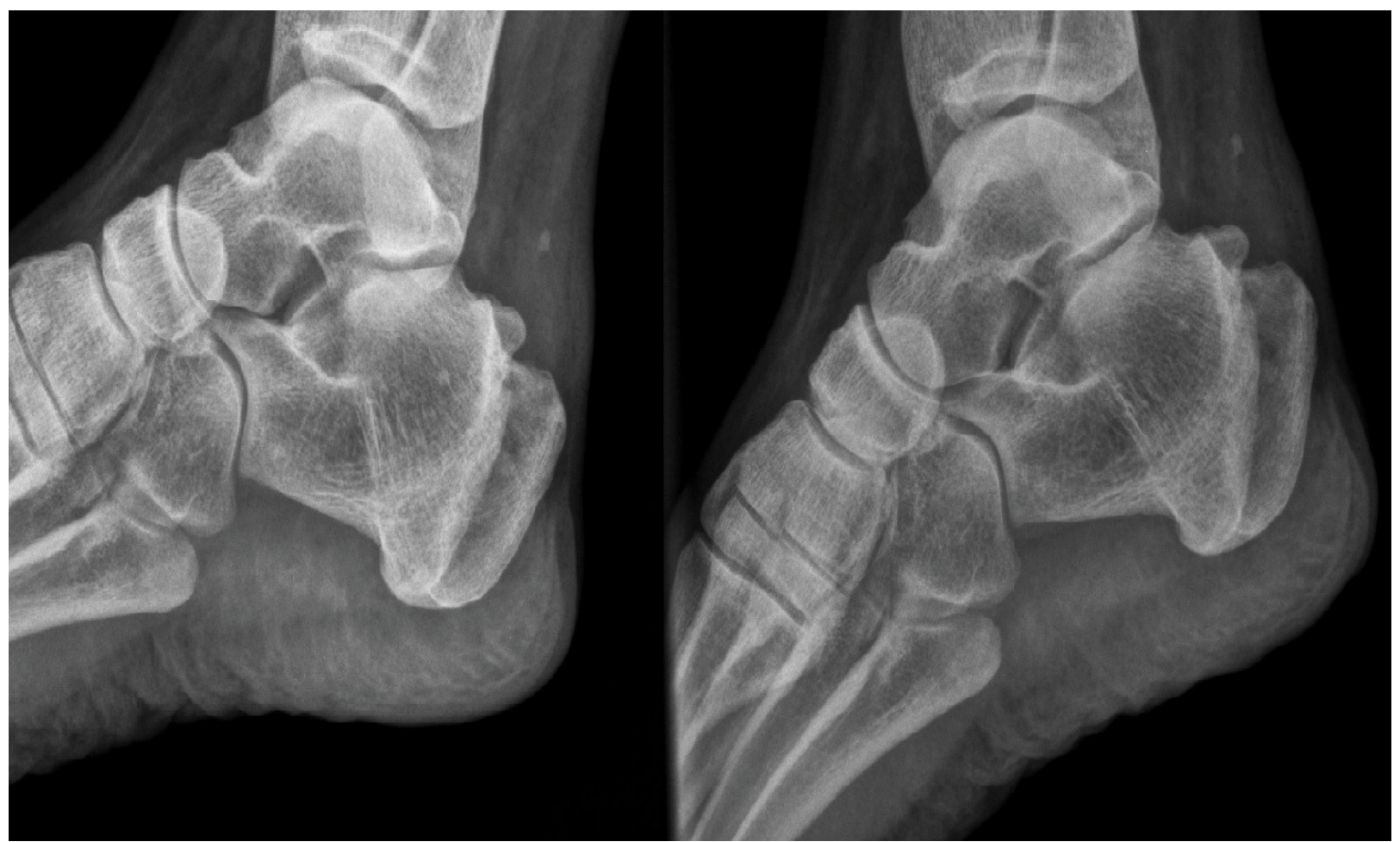

Figure 3: Case 2: In a 38-year-old female, after 20 sessions of treatment, pain decreased from $10 / 10$ to $2 / 10$ and size of calcification decreased from 3 to $2 \mathrm{~mm}$. 

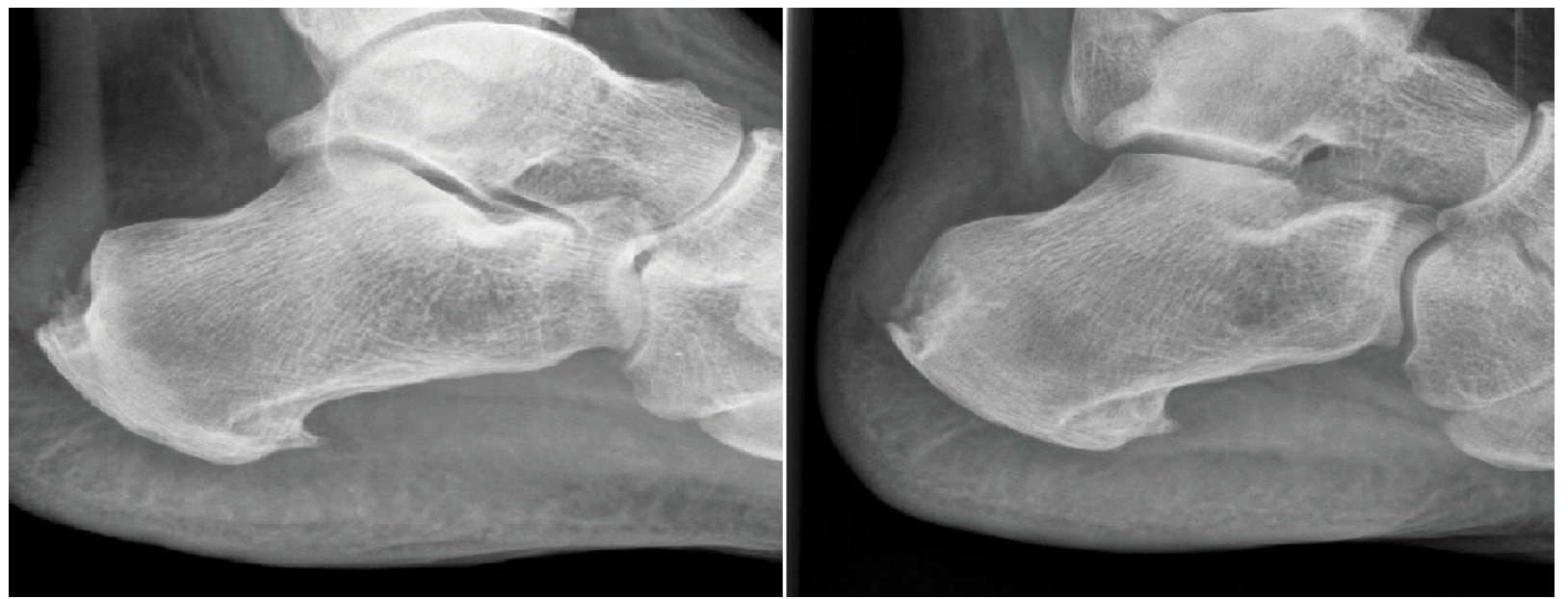

Figure 4: Case 3: In a 47-year-old male, after 20 sessions of treatment, pain decreased from 7/10 to 4/10 and size of calcification decreased from 10 to $0 \mathrm{~mm}$.
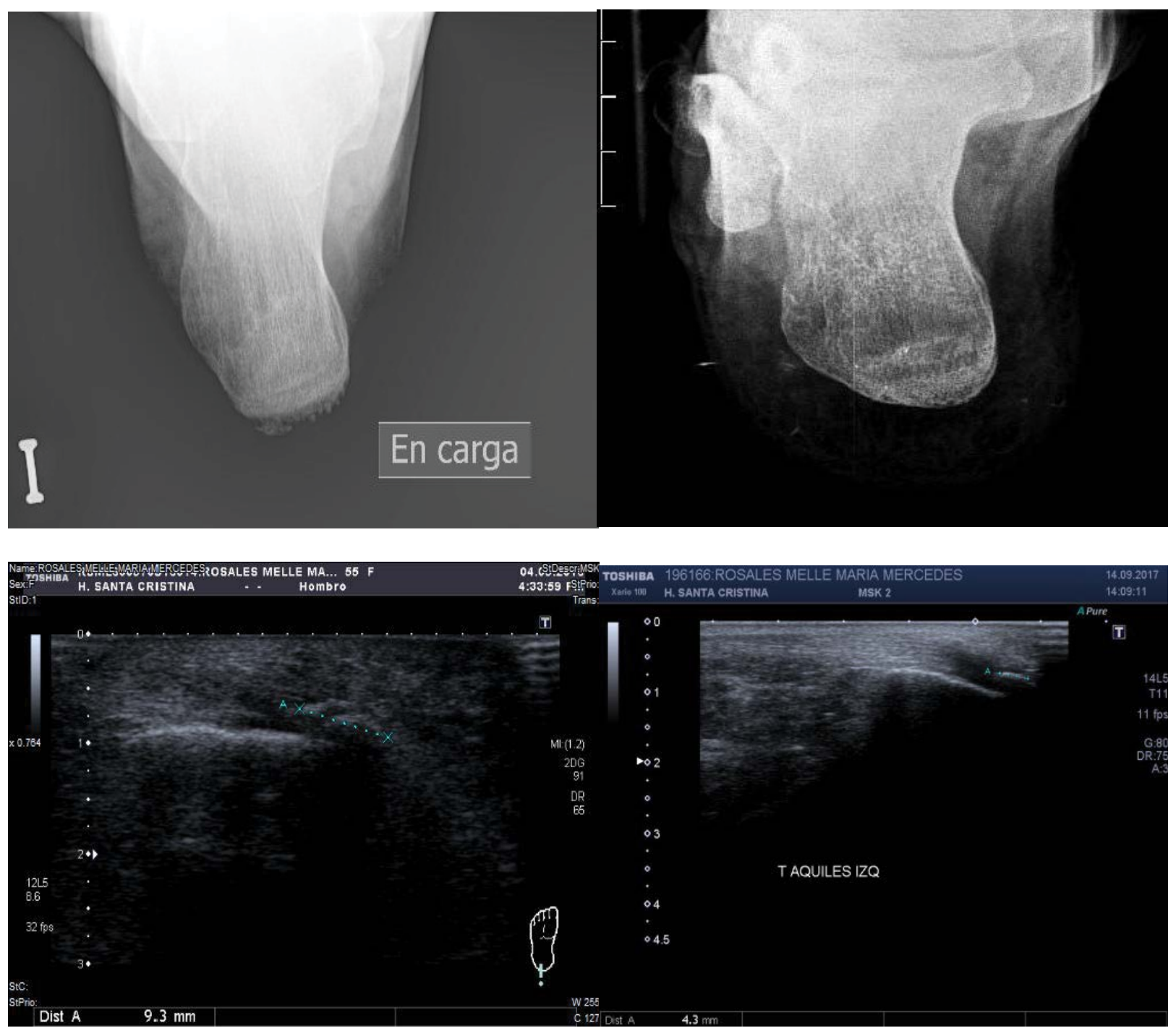

Figure 5: Case 4: In a 57-year-old female, after 15 sessions of treatment, pain decreased from $9 / 10$ to $4 / 10$ and size of calcification decreased from 9 to $4 \mathrm{~mm}$, evaluated by sonography.

produces great socio economic impact [16], great demand and high use of resources [17] and labor absenteeism [8], being pain the leading cause of disability due to loss of mobility [8]. Some authors argue that pain could remain in $50 \%$ of cases up to a year after onset [14], while others claim that CT could evolve spontaneously toward healing between 3 and 10 years [18]; this fact worsens patients' quality of life in their personal, family and work aspects [8]. In the case of Achilles tendon, subcutaneous bursa is the most 
innervated tissue at the back of the heel, where patients refer disabling pain.

CT is common in middle-aged working patients (between $30-50$ years) $[7,8,16]$, as it was in the present trial (49 years). CT is more common in women $[8,16,19-$ 21]; however, it was similar in our series $(n=50 \%)$.

The presence of CT on other articulations different from the shoulder is rare. Only a few case reports make note of these infrequent presentation (CT at the hip and at Achilles tendon). To date, there are neither reports on prevalence nor clinical outcomes on CT of the wrist, elbow or patella. This is the first study that states the effectiveness and safeness of $5 \%$ acetic acid iontophoresis in Achilles' tendon, and in a prospective series of cases $(n=10)$ (Figures 2, Figure 3, Figure 4, Figure 5 and Figure 6).

Calcific tendinopathy involves the substance of the tendon and is particularly common in the rotator cuff (shoulder) [5]; whereas insertional calcific tendinopathy involves the deposit of calcium at the enthesis, affecting predominantly the Achilles tendon, the common extensor tendon at the elbow, the gluteus medium and mini- mum at the greater trochanter and the patellar tendon [5]. Indeed, most of CT occurs at the insertion of the tendon, and it is related to the degree of force transmitted to the tendon [4]. CT is related to a degenerative change, which is commonly seen in the Achilles, the rotator cuff, the patella and the extensor carpi radialis brevis (tennis elbow) [4]. The location of tendons affected by CT in decreasing order of frequency includes the shoulder, hip, ankle, elbow, wrist and knee [1]. In the case of CT of the shoulder, the supraspinatus tendon is the most affected, followed by infraspinatus and subscapularis tendon $[8,10,20,22,23]$. There subsides the importance of describing such and odd prevalence.

The radiological diagnosis of $\mathrm{CT}$ is made by radiography or ultrasound. $\mathrm{MRI}$ is only indicated in cases of suspected association with muscle/tendon pathology $[7,8]$. The various radiological classifications agree that the type I corresponds to located deposits, well-defined contours, dense texture and homogeneous consistency; whereas type II corresponds to scattered deposits, not-well-defined contours, cloudy consistency and heterogeneous texture [10]. This radiological characterization is important because type II (resorptive)
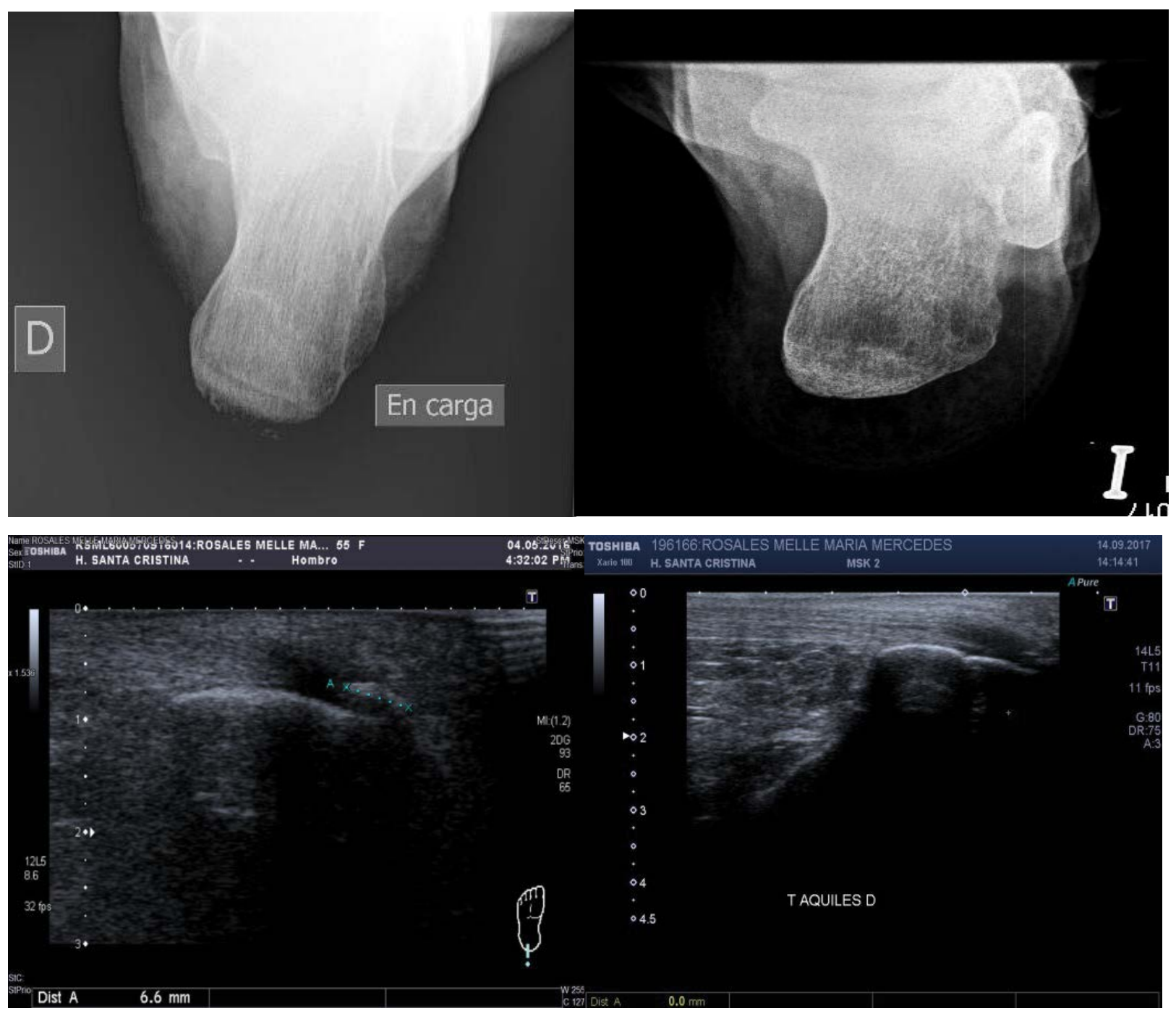

Figure 6: Case 5: In a 57-year-old female, after 15 sessions of treatment, pain decreased from 5/10 to $0 / 10$ and size of calcification decreased from 6 to $0 \mathrm{~mm}$, evaluated by sonography. 
has a better prognosis than type I (formative) [10].

CT treatment is controversial. A recent article has demonstrated the effectiveness of different Rehabilitation techniques to reduce pain but not the calcification on shoulder CT [8]. Until now, the only option used in the treatment of calcification was acetic acid iontophoresis. However, there are only three classic studies that assess their effectiveness; one favorably (Rioja-Toro) [11], and two unfavorably (Perrón and Leduc) [14,15]. In fact, Leduc and Perrón stated that acetic acid iontophoresis produced neither relief in pain nor decreased in calcification size. Recently, two different studies, conducted by Chico-Alvarez and Fernández-Cuadros have demonstrated that Acetic Acid lontophoresis produced relief in pain and decreased in calcification size in CT of the shoulder $[7,10]$. However, to the best of our knowledge, there are only some case reports on the effectiveness of this treatment on $\mathrm{CT}$ in gluteus medium and minimum tendon [24] and in Achilles tendon [25], with promising results. Meanwhile, there is no report on the effectiveness on elbow, wrist or knee CT. There subsides the importance of this multicenter non-randomized before-and-after control trial.

lontophoresis is a noninvasive technique that increases the penetration of transdermal substances (drugs) through the skin layers (epidermis, dermis and hypodermis) in a controlled manner and with the help of the application of electric current, based on physicalchemical principles of attraction and repulsion of charges [26]. Its most common applications are: 1) Calcifying tendinitis and 2) Myositis ossificans (with acetic acid as a therapeutic agent) [27]. This technique is cheap because of the economic use of topical medications and because the electrotherapy equipment has decreased in size and has become more accessible due to low-productioncosts [28].

The application of Ultrasound to the skin increases its permeability and facilitates diffusion of different drugs/substances into the skin. This transport is called sonoferesis [29]. Low frequency sonoferesis works synergistically with iontophoresis; Le, et al. used Ultrasound 10 minutes prior to the application of iontophoresis with good results [30].

Psaki and Carrol (in 1955) introduced acetic acid iontophoresis as an effective treatment in shoulder CT $[14,15,31]$. Kahn postulated that insoluble calcium carbonate precipitates could become soluble salts of calcium acetate, which could favor the reabsorption of the calcification [31]: $\mathrm{CaCO}_{3}+2 \mathrm{H}\left(\mathrm{CaH}_{3} \mathrm{O}_{2}\right)_{2}=\mathrm{Ca}\left(\mathrm{C}_{2} \mathrm{H}_{3} \mathrm{O}_{2}\right)$ ${ }_{2}+\mathrm{H}_{2} \mathrm{O}+\mathrm{CO}_{2}$. Furthermore, the use of ultrasound for their mechanical and thermal effects could help disintegrate and reabsorb calcification due to increase in local vascularization [11].

The proposed study protocol (2 cc of $5 \%$ acetic acid lontophoresis at $4.7 \mathrm{mAx} 10$ minutes, followed by continuous ultrasound $1 \mathrm{~W} / \mathrm{cm}^{2} / 1 \mathrm{MHz} \times 5$ minutes) [7] differs from those of Rioja-Toro [11] (3 cc of $5 \%$ acetic acid iontophoresis for $20 \mathrm{~min}$ at $4.7 \mathrm{~mA}$ plus ultrasound $1.5 \mathrm{~W} / \mathrm{cm}^{2}$ ), Perron [12] (5\% acetic acid iontophoresis (not specified amount) at $5 \mathrm{~mA} \times 20$ minutes followed by ultrasound $0.8 \mathrm{~W} / \mathrm{cm}^{2} \times 5$ minutes), Leduc [13] (5\% acetic acid iontophoresis, $2 \mathrm{cc}$ at $5 \mathrm{~mA} \times 15-20$ minutes without ultrasound) and Chico-Alvarez (5\% acetic acid iontophoresis (not specified amount) at $4.7 \mathrm{~mA}$ for 20 minutes without ultrasounds) [1]. As a resume, all authors applied acetic acid at a 5\% concentration, and the dose used was between 2 to $3 \mathrm{cc}$.

The average number of sessions in our series was 21.7 (from 10 to a maximum of 30 sessions). The criterion to continue or discontinue treatment was the radiological evolution. Perrón treated his patients for 9 sessions ( 3 sessions/week for 3 weeks) [12]. Leduc treated them for 10 sessions (3/week the first two weeks, and then weekly for 4 weeks) [13]. Rioja-Toro treated his patients for 40 sessions ( 5 times a week) and evaluated them at 20 and at 40 sessions [11]. Chico-Alvarez treated his patients between 15 and 30 sessions depending on the radiological evolution (5 times a week) [10]. The failure from the protocols of Perrón and Leduc were probably because 9 and 10 sessions were insufficient to get the desired goals (to reduce pain and calcification size). That would explain why Rioja-Toro, Chico-Alvarez and Fernández-Cuadros have gotten such a success in their studies (the greater the sessions, the better success).

To the best of our knowledge, the present study supports the highest number of patients published up-to-date. The importance lies in the difficulty of prospectively collect such a number of patients. Perrón [12] studied 21 patients; Leduc [13] 36 patients, Rioja-Toro [11] recruited 34 patients; Chico-Álvarez [10] studied 25 patients for each control group, and Fernández-Cuadros 44 patients [7]. We recruited 10 patients in a two years prospective study (54 months).

The present study has demonstrated that Acetic Acid lontophoresis is effective in diminishing pain and size of calcification for the first time in CT of the ankle. This find is in accordance with a recent Systematic Review and a Meta-Analysis, which sustains that lontophoresis is effective in the treatment of pain for musculoskeletal disorders [32].

Methodologically, a quasi-experimental before and after study (or Non-Randomized Control Trial) is considered an intervention intended to evaluate the impact of an intervention. It is more simple and cheaper than a Clinical Trial. It is the only way to perform a study when ethical problems or feasibility to perform randomization come to light. This pretest-posttest design is considered "intra-subject" study, there is only one group, and therefore the observations are made before and after the intervention. No randomization is feasible since only a group is studied. However, as this is an experimental 
study, it gives a good level of based-evidence. The Canadian Task Force on Preventive Health Care gives this studies an II-1 level of evidence [33,34].

\section{Study Limitations}

An important limitation of the study is the absence of control group. This is mainly due to the limited number of cases. In fact, 54 months-follow-up was needed to collect such a sample. As the effectiveness of acetic acid Iontophoresis on $\mathrm{CT}$ is for decades recommended, and all patients accepted the treatment, it was not ethical to deny the intervention. A quasi-experimental before and after intervention study (also referred to as a nonrandomized control trial) is applied in this specific situation, to solve the lack of control group, and to give clinical based evidence. Despite the sample size and the methodological type of study, those variables do not affect the results observed in our study.

We encourage researchers to conduct studies like ours to reproduce our findings, and to increase consistency and demonstrable clinical-based-evidence, given the encouraging results observed in this study.

\section{Conclusions}

$\mathrm{CT}$ is more common in middle-aged people. In our study, CT affects similarly both male and female. CT affects insertional tendons as in the case of Achilles. lontophoresis with 5\% Acetic Acid and Ultrasound is a safe, simple and inexpensive technique capable to reduce significantly pain and size of calcification on the ankle. This study shows a level of evidence II- 1 and grade of recommendation $B$ that allows us to postulate Acetic Acid Iontophoresis and Ultrasound as an effective treatment in $\mathrm{CT}$ of the ankle.

\section{Acknowledgement}

To the physiotherapists C. Ramos-Gonzalez, C. Calabozo-Alvaro, L. Hernández-Gomez, A. ZurikaraiMontes, L. García-Turrion, A. ArocenaMunduate, N. Sanchez-Martin; and to the auxiliars A. Pacho-Santiago, M. Haro-Rodriguez, F. Gonzalez-Cunha and P. TapiaGonzalez; workers of the Rehabilitation Service, Santísima Trinidad's General Foundation Hospital, and to all the Physiotherapist at Santa Cristina's University Hospital, for their dedication, professionalism and vocation; without their help, this treatment protocol could not have been done.

\section{Conflicts of Interest}

\section{The authors declare no conflict of interest.}

We certify that no party having a direct interest in the results of the research supporting this article has or will confer a benefit on us or on any organization with which we are associated AND, if applicable, we certify that all financial and material support for this research (eg, NIH or NHS grants) and work are clearly identified in the title page of the manuscript.
The legal/regulatory status of the device(s) that is/ are subject of this manuscript is/are not known by the author(s).

\section{References}

1. Olsen KM, Chew FS (2006) Tumoral calcinosis: Pearls, polemics, and alternative possibilities. Radiographics 26 : 871-885.

2. Flemming DJ, Murphey MD, Shekitka KM, Temple HT, Jelinek JJ, et al. (2003) Osseous involvement in calcific tendinitis: A retrospective review of 50 cases. Am J Roentgenol 181: 965-972.

3. Krasny C, Enenkel M, Aigner N, Wlk M, Landsiedl F (2005) Ultrasound-guided needling combined with shock-wave therapy for the treatment of calcifying tendonitis of the shoulder. J Bone Joint Surg Br 87: 501-507.

4. Rees JD, Wilson AM, Wolman RL (2006) Current concepts in the management of tendon disorders. Rheumatology 45 : 508-521.

5. Bureau NJ (2013) Calcific tendinopathy of the shoulder. In Seminars in musculoskeletal radiology, Thieme Medical Publishers 17: 080-084.

6. Uhthoff HK, Loehr JW (1997) Calcific tendinopathy of the rotator cuff: Pathogenesis, diagnosis, and management. J Am Acad Orthop Surg 5: 183-191.

7. Fernández Cuadros ME, Pérez Moro OS, Alava Rabasa S, García González JM, Mirón Canelo JA (2016) Calcifying tendonitis of the shoulder: Risk factors and effectiveness of acetic acid iontophoresis and ultrasound. Middle East $\mathrm{J}$ Rehabil Health, (inpress).

8. Fernández Cuadros ME, Pérez Moro OS, Nieto Blasco J, Rivera Garcia V, Olazar Pardeiro, et al. (2015) A calcifying tendonitis of the shoulder: Risk factors and effectiveness of physical therapy. Occup Med Health Aff 3: 220.

9. Cho NS, Lee BG, Rhee YG (2010) Radiologic course of the calcific deposits in calcific tendinitis of the shoulder: Does the initial radiologic aspect affect the final results? J Shoulder Elbow Surg 19: 267-272.

10. Chico Alvarez E (2015) Estudio prospectivo comparando los tres resultados obtenidos con tres tratamientos de electroterapia en las tendinopatías calcificadas del supraespinoso. Tesis Doctoral Valladolid.

11. Rioja Toro J, Romo Monje M, Cantalapiedra Fuentes E, Gonzalez Rebollo AY, Blázquez Sanchez E (2001) Tratamiento de la tendinitis calcificante del hombro mediante iontoforesis con ácido acético y ultrasonidos. Rehabilitación 35: 166-170.

12. Perron M, Malouin F (1997) Acetic acid iontophoresis and ultrasound for the treatment of calcifying tendinitis of the shoulder: A randomized control trial. Arch Phys Med Rehabil 78: 379-384.

13. Leduc BE, Caya J, Tremblay S, Bureau NJ, Dumont M (2003) Treatment of calcifying tendinitis of the shoulder by acetic acid iontophoresis: A double-blind randomized controlled trial. Arch Phys Med Rehabil 84: 1523-1527.

14. Tashjian RZ, Deloach J, Porucznik CA, Powell AP (2009) Minimal clinically important differences (MCID) and patient acceptable symptomatic state (PASS) for visual analog scales (VAS) measuring pain in patients treated for rotator cuff disease. J Shoulder Elbow Surg 18: 927-932.

15. Dworkin RH, Turk DC, Wyrwich KW, Beaton D, Cleeland CS, et al. (2008) Interpreting the clinical importance of 
treatment outcomes in chronic pain clinical trials: IMMPACT recommendations. J Pain 9: 105-121.

16. Jiménez García D, López Dolado E, López Zarzuela MC (2008) Tratamiento de la tendinopatía calcificante de hombro: ¿ iontoforesis con ácido acético u onda corta? Rehabilitación 42: 239-245.

17. Vicente Herrero MT, García LC, González ÁL, de la Torre (2009) MRIEI hombro y sus patologías en medicina del trabajo. SEMERGEN-Medicina de Familia 35: 197-202.

18. Cacchio A, De Blasis E, Desiati P, Spacca G, Santilli V, et al. (2009) Effectiveness of treatment of calcific tendinitis of the shoulder by disodium EDTA. Arthritis Rheum 61: 84-91.

19. Barrera Cárdenas JI, Campa Rodríguez AY, García Prendes V (2010) Resultados del tratamiento artroscópico de las tendinitis calcificantes del manguito de los rotadores del hombro. Rev Esp Cir Ortop Traumatol 54: 93-148.

20. Ferrera CE, Ricard F (2009) Estudio comparativo de pruebas ortopédicas para la valoración y confirmación diagnóstica de tendinopatía del músculo supraespinoso. Osteopatía científica 4: 86-92.

21. Arrebola AP, Martínez Rodríguez ME (2005) Tratamiento de tendinitis y bursitis calcificadas subacromiodeltoideas con ondas de choque. Rehabilitación 39: 2-7.

22. Martín AJ, Yubero FJS, Carmona MZ, Cid FJN, Asensi FJC, et al. (2012) Tratamiento de la tendinitis calcificante de hombro mediante artroscopia. Trauma 23: 32-38.

23. Adamietz B, Schulz Wendtland R, Alibek S, Uder M, Sauer $R$, et al. (2010) Calcifying tendonitis of the shoulder joint. Strahlentherapie und Onkologie 186: 18-23.

24. Anap Deepak B, Gandge SG, Wagh Nitin J (2010) Treatment of calcifying tendinitis of Gluteus medius and gluteus minimus by acetic acid iontophoresis-A case study. Indian Journal of Physiotherapy and Occupational Therapy 4: 22-24.

25. Kilfoil RL Jr, Shtofmakher G, Taylor G, Botvinick J (2014) Acetic acid iontophoresis for the treatment of insertional achilles tendonitis. BMJ case reports.

26. Krueger E, Claudino Junior JL, Scheeren EM, Neves EB, Mulinari E, et al. (2014) lontophoresis: Principles and applications. Fisioterapia Em Movimento 27.

27. Dehghan M, Mouzam M (2008) Advances in iontophoresis for drug delivery. International Journal of Health Research 1.

28. Gratieri T, Gelfuso GM, Lopez, RFV (2008) Princípios básicos e aplicação da iontoforese na penetraçãocutânea de fármacos. Quim Nova 31.

29. Pahade A, Jadhav VM, Kadam VJ (2010) Sonophoresis: An overview. Int J Pharm Sci Res 3: 24-32.

30. Le L, Kost J, Mitragotri S (2000) Combined effect of lowfrequency ultrasound and iontophoresis: Applications for transdermal heparin delivery. Pharm Res 17: 1151-1154.

31. Kahn J (1957) Acetic acid iontophoresis for calcium deposits. Phys ther 57: 658-659.

32. Clijsen R, Taeymans J, Baeyens JP, Barel AO, Clarys, $P$ (2012) The effects of iontophoresis in the treatment of musculoskeletal disorders-a systematic review and metaanalysis. Drug Delivery Letters 2: 180-194.

33. Manterola, Carlos, Otzen, Tamara (2015) Estudios experimentales 2 parte: Estudios cuasi-experimentales. Int J Morphol 33: 382-387.

34. Mirón Canelo JA (2013) Sistema de Información Sanitaria. Indicadores de Salud, Bienestar y Calidad de Vida. En: Guías para la Elaboración de trabajos científicos, Grado, Master y Posgrado. Salamanca, España: Gráficos Lope. 